\begin{tabular}{|c|l|}
\hline Title & Liquid-vapor structure near heating surface at high heat flux in subcooled pool boiling \\
\hline Author(s) & Ono, Ayako; Sakashita, Hiroto \\
\hline Citation & $\begin{array}{l}\text { International Journal of Heat and Mass Transfer, 50/17-18), 3481-3489 } \\
\text { https://doi.org/10.1016/.ijheatmasstransfer.2007.01.026 }\end{array}$ \\
\hline Issue Date & 2007-08 \\
\hline Doc URL & http://hdl.handle.net/2115/28147 \\
\hline Type & article (author version) \\
\hline File Information & IJHM50-17-18.pdf \\
\hline
\end{tabular}

Instructions for use 


\section{Liquid-Vapor Structure near Heating Surface at High Heat Flux in Subcooled Pool Boiling}

Ayako $\mathrm{Ono}^{\mathrm{a}}$ and Hiroto Sakashita ${ }^{\mathrm{a}, *}$

a Division of Energy and Environmental Systems, Graduate School of Engineering,

Hokkaido University, North 13 West 8, Kita-ku, Sapporo 060-8628, Japan

* Corresponding author. Tel.: +81 11706 6664; fax.: +81 117066664

E-mail address: saka@eng.hokudai.ac.jp 


\title{
Liquid-Vapor Structure near Heating Surface at High Heat Flux in Subcooled Pool Boiling
}

\begin{abstract}
Liquid-vapor behavior close to a heating surface was measured using two conductance probes with tip diameters smaller than $5 \mu \mathrm{m}$. Measurements were carried out for water boiling on an upward-facing copper surface under subcooling from 0 to $30 \mathrm{~K}$. The probe signals and the void fraction distributions showed that there is little difference in the liquid-vapor structure beneath large vapor masses in saturated and subcooled boiling, that a macrolayer remains on the heating surface, and that in subcooled boiling it does not dry out even at heat fluxes far higher than at CHF for saturated boiling. The thickness of the macrolayer forming beneath large vapor masses was determined from the location where the probe signals corresponding to the large vapor masses disappear. It was found that the thicknesses of the macrolayer formed in subcooled boiling are comparable to or thicker than those near the $\mathrm{CHF}$ in saturated boiling, and it is considered that this is most likely to be one of the causes why the CHF increases with the increasing subcooling.
\end{abstract}

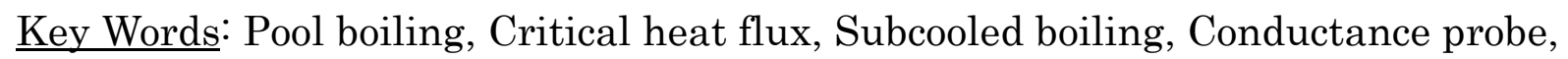
Macrolayer

\section{Nomenclatures}

h: height from heating surface $\quad \mathrm{q}$ : heat flux $\quad \mathrm{qCHF}_{\mathrm{CH}}$ : critical heat flux

$\mathrm{T}_{\mathrm{me}}:$ measurement time $\quad \Delta \mathrm{T}_{\mathrm{sub}}:$ subcooling 


\section{Introduction}

There are numerous studies of CHF in pool boiling, but the mechanism of this phenomenon has not been fully elucidated. In saturated pool boiling on an upward-facing surface, large vapor masses form and detach periodically from the heating surface above a heat flux of $20-40 \%$ of the CHF, and a thin liquid-rich zone, a so-called macrolayer, exists beneath the large vapor masses. It is generally accepted that this macrolayer is closely related to the occurrence of $\mathrm{CHF}$ in saturated boiling. Therefore, attempts have been made to determine the liquid-vapor structure under the vapor masses in saturated boiling, using electric conductance probes $[1,2,3,4]$ and an optical probe [5] for the measurements because the vapor masses hovering on the heating surface make it impossible to conduct direct observations of the macrolayer from above the heating surface. These measurements have confirmed the presence of the macrolayer under the vapor masses, however, the detailed structure and dynamics of the macrolayer have not been fully described as the macrolayer is very thin making it difficult to determine the structure accurately.

Large vapor masses are also observed in subcooled pool boiling. With 10 mm diameter circular disks, Inada et al. [6], Yokoya et al. [7], and Li et al. [8] confirmed that the large vapor masses are formed and detach or collapse periodically on the heating surface when the subcooling is less than about $50 \mathrm{~K}$ and the heat flux is close to the CHF. Despite the similarities in the boiling conditions in saturated and subcooled boiling, it has been established that with increases in subcooling the CHF for subcooled boiling markedly increases above the CHF for saturated boiling. The causes of the increase in CHF with increases in subcooling could be related to the liquid-vapor structure beneath the vapor masses, but no research has been addressed at clarifying the CHF mechanism 
based on measurements of the liquid-vapor structure. This study aims to examine the mechanism of CHF for saturated and subcooled pool boiling. The liquid-vapor behavior close to the heating surface was measured with highly accurate conductance probes for pool boiling of water on an upward surface in the range of subcooling from 0 to $30 \mathrm{~K}$. Through these measurements, the thickness of the macrolayer that forms beneath the vapor masses at high heat fluxes near the CHF was determined.

\section{Experiment}

\subsection{Experimental apparatus}

Figure 1 shows the experimental apparatus. The experiments were conducted using water at atmospheric pressure over a range of subcooling from 0 to $30 \mathrm{~K}$. The boiling vessel is made of Pyrex glass with an inner diameter of 210 $\mathrm{mm}$, filled with deionized water to a depth of $200 \mathrm{~mm}$ high. The subcooling of the liquid was achieved with auxiliary heaters and cooling pipes placed in the vessel. The subcooling was defined by the liquid temperature measured at the same height as the heating surface, $20 \mathrm{~mm}$ from the center of the surface. The top surface of a conical copper block served as the heating surface making it possible to realize a heat flux up to $10 \mathrm{MW} / \mathrm{m}^{2}$. The diameter of the heating surface is 8 $\mathrm{mm}$ and a vapor mass may cover the whole of the area of the heating surface at high heat fluxes near the CHF at the $30 \mathrm{~K}$ subcooling in the present experiment. Three thermocouples of $0.5 \mathrm{~mm}$ diameter were embedded in the copper block 5,13 , and $21 \mathrm{~mm}$ below the heating surface. The surface temperature and heat flux were calculated with the three thermocouples by considering the conical copper block as approximating a part of a hollow sphere. The heating surface was polished by \#1000 emery paper before each experiment. 
A conductance probe method was adopted for the measurements of the liquid-vapor behaviors very close to the heating surface. The sensing element of the conductance probe, which is a $90 \mu \mathrm{m}$ diameter stainless steel wire, was inserted in a conical capillary quarts tube with very low thermal expansion coefficient. The tip of the stainless steel wire was exposed about $1 \mathrm{~mm}$ from the tip of the quarts tube. It is desirable to make the probe tip as thin as possible, to improve the space resolution and to reduce the influence of liquid adhesion at the tip of the probe. In this study, the tip of the stainless steel wire was thinned to less than $5 \mu \mathrm{m}$ by an electro-polishing technique. This conductance probe was connected to a three-dimensional moving stage with an accuracy of $0.5 \mu \mathrm{m}$ in the perpendicular direction and $10 \mu \mathrm{m}$ in the horizontal direction (the moving probe in the followings, A-probe in Fig.1). A further probe was used to selectively measure the behaviors of vapor masses (fixed probe in the following, B-probe in Fig.1). The fixed probe was placed near the center of the heating surface $4 \mathrm{~mm}$ over the surface. The support rods of the moving prove and of the moving stage

were a nickel alloy (Super Inver) with a thermal expansion coefficient of about 0.5 $\times 10^{-6} / \mathrm{K}$, two orders of magnitude smaller than those of usual metals. During the measurements, potassium chloride was added to increase the electro conductivity of the water, and an AC voltage was imposed between the heating surface and each of the two probes.

\subsection{Measurement circuit}

Figure 2 is a schematic diagram of the measurement circuit. To improve the sensitivity of the measurements, the frequency of the $\mathrm{AC}$ voltage applied to the probes was adjusted to the resonance frequency of the measurement circuit, the resonance frequency was adjusted to $24 \mathrm{kHz}$ by inserting inductances, and the 
inverse of this frequency, $42 \mu \mathrm{s}$, is the time resolution of the measurements. The position of the moving probe was calibrated by the electrical contact between the probe tip and the heating surface by using a short detection circuit which detects a moment just when the peak voltage and/or the frequency of the probe signals become lower than a given threshold value. The probe position was checked repeatedly during a run under the condition that the heating surface was heated by a set heat flux. The reproducibility of the probe position was excellent and errors were within $0.5 \mu \mathrm{m}$, the limit of accuracy of the micrometer attached to the moving stage.

The raw $24 \mathrm{kHz}$ signals from the moving and fixed probes were digitized with an adequate threshold voltage (Schmidt trigger level) by comparator circuits and converted into continuous signals by RE TRIG. S/S (re-triggerable single shot) circuits. Examples of raw signals from the probes and the converted digitized signals are shown in Fig.3, where a high voltage of the raw signals shows that the tip of a probe is in contact with vapor and a low voltage that it is in contact with liquid. In Fig.3, the black signals represent the raw signals and the digitized binary signals of the moving probe measured at $0.051 \mathrm{~mm}$ over the heating surface under a heat flux of $\mathrm{q}=2.55 \mathrm{MW} / \mathrm{m}^{2}$ and subcooling of $\Delta \mathrm{T}_{\text {sub }}=20 \mathrm{~K}$. The simultaneously measured fixed probe signals are shown in gray below the moving probe signals. The threshold voltage of the comparators to digitize the raw signals was set to $30 \%$ of the maximum signal voltage, and signals higher/lower than this voltage are regarded as vapor/liquid signals. In this paper, a high digitized probe signal is termed a pulse, and its width is the pulse width. The width and the arrival time of pulses from the moving probe are acquired in a pulse width scaler with a minimum time resolution of $1 \mu \mathrm{s}$, much shorter than the time resolution of $42 \mu$ s determined from the resonance frequency of the electrical 
circuit. The digitized signals of the moving and the fixed probes were stored simultaneously in the $\mathrm{PC}$ through the $\mathrm{A} / \mathrm{D}$ converters enable calculation of the void fraction during vapor mass hovering.

\section{Results and discussion}

\subsection{Boiling curves and critical heat fluxes}

Figure 4 shows the boiling curves measured in the experiments. In the fully developed nucleate boiling region, the boiling curves of different subcoolings almost overlap and lie close to the results predicted with the correlation for water by Stephan and Abdelsalam [9]. Figure 5 shows the present data of the CHF together with previously measured data by Inada et al.[6], Yokoya et al.[7], and Li et al.[8] for an upward-facing $10 \mathrm{~mm}$ diameter heating surface. Both the present and the previously measured $\mathrm{CHF}$ increase monotonously with increases in subcooling.

The various results for the $20 \mathrm{~K}$ and $30 \mathrm{~K}$ subcoolings shown in the following sections were obtained in the region of heat fluxes higher than the CHF for saturated boiling $\left(\mathrm{q}_{\mathrm{CHF}}=2.09 \mathrm{MW} / \mathrm{m}^{2}\right)$.

\subsection{Changes in probe signals at different heights}

Figure 6 shows the probe signals measured at different heights over the heating surface, continuous about $30 \mathrm{~ms}$ wide vapor signals corresponding to detached vapor masses, are observed far from the heating surface ( $h \geqq 0.241 \mathrm{~mm}$ ). As the probe approaches the heating surface, the vapor mass signals display discontinuities $(\mathrm{h}=0.141 \mathrm{~mm})$. When approaching the surface further, the wide pulses disappear and the signals appear as an aggregation of narrow pulses $(\mathrm{h}=0.051 \mathrm{~mm}, 0.031 \mathrm{~mm})$. Finally, close to the surface, high voltage signals have 
disappeared and there are only the fine low voltage signals, indicating that there is only liquid at this height $(\mathrm{h}=0.011 \mathrm{~mm})$.

Figure 7 shows the distributions of the pulse frequencies and the average pulse widths measured under similar condition as the measurements in Fig.6 $\left(\mathrm{q}=2.55 \mathrm{MW} / \mathrm{m}^{2}\right.$ and $\left.\Delta \mathrm{T}_{\mathrm{sub}}=20 \mathrm{~K}\right)$. The average pulse width decreases monotonously toward the surface, and the pulse frequency initially increases to reach a maximum and then decreases rapidly. Bhat et al. [3] measured the contact frequency of a probe tip with vapor, and obtained results similar to those in Fig.7. Bhat et al. interpreted this to show that the increase in the frequency is caused by primary bubbles which are formed and merge with the vapor mass and that the rapid decrease in frequency is due to interference of the probe tip with the growth process of the primary bubbles. As shown in Fig.6, however, the increase in the frequency is caused by an increase in the number of discontinuities in the vapor mass signals. Further, the signals obtained near the height where the frequency reaches the maximum value $(\mathrm{h}=0.051 \mathrm{~mm})$ still maintains the shape of the vapor mass signals, and below this height there is a liquid layer where the probe indicates an absence of primary bubble generation. Therefore, the high frequency of the pulse signals may be caused by intermittent contact of the probe tip with liquid/vapor due to the violent oscillation of the bottom of the vapor mass hovering on the heating surface rather than the formation and detachment of primary bubbles.

\subsection{Void fraction distribution near the heating surface during vapor mass hovering}

The time averaged void fractions measured by a single probe includes the probe signals during the waiting period from the departure of a vapor mass to the 
formation of the following vapor mass. In the present experiment, with an $8 \mathrm{~mm}$ diameter heating surface, the waiting period measured near $\mathrm{CHF}$ was about $8 \mathrm{~ms}$ for subcooling $\Delta \mathrm{T}_{\mathrm{sub}}=0 \mathrm{~K}$ and $10 \mathrm{~K}$, about $13 \mathrm{~ms}$ for $\Delta \mathrm{T}_{\mathrm{sub}}=20 \mathrm{~K}$, and about $20 \mathrm{~ms}$ for $\Delta \mathrm{T}_{\mathrm{sub}}=30 \mathrm{~K}$. These void fractions including the effect of the waiting time are not acceptable when examining the liquid-vapor structure beneath the vapor mass. In the present study, therefore, the time averaged void fractions were calculated from the moving probe signals for the period where the fixed probe indicated vapor mass signals. Figure 8 shows the distribution of the time averaged void fractions during the vapor mass hovering. The void fraction distributions are similar for all subcooling conditions: it has a value around unity far from the surface and decreases monotonously as it approaches the heating surface. Close to the heating surface, the void fraction reaches zero or a constant value very close to zero, indicating that even at high heat fluxes, exceeding the CHF for saturated boiling, the center of the heating surface is not dried out during the vapor mass hovering but that it is covered by a liquid layer. Overall the results show that the waiting periods of vapor mass formation are different at saturated and subcooled boiling, but that there is no large discrepancy in the liquid-vapor structure beneath the vapor mass when the vapor mass covers the heating surface.

In Fig.8, the distance from the heating surface to the height where the void fraction becomes zero, or a constant value close to zero, may correspond to the minimum thickness of the liquid layer that remains stationary on the surface without drying out during the vapor mass hovering. Figure 9 shows this minimum liquid layer thickness versus the heat flux. The arrows in the figure indicate the $\mathrm{CHF}$ at each subcooling condition. The data scatters somewhat, but the minimum liquid layer thickness tends to approach zero with increasing heat 
flux at each subcooling condition, which is not inconsistent with the macrolayer dryout model.

\subsection{Hovering period of vapor masses}

Figure 10 shows examples of the spectrums of the pulse width measured by the moving probe $4 \mathrm{~mm}$ over the heating surface (corresponding to the approximate position of the center of the vapor mass) and also just over the heating surface. (In the spectrum graphs of Figs. 10, 11, 14, and 15, the vertical axes express the total number of pulses counted within the measurement time $\mathrm{T}_{\mathrm{me}}$ ). All the spectrums obtained at $4 \mathrm{~mm}$ have a peak around a pulse width of about 20 to $30 \mathrm{~ms}$ and there is no such peak near the heating surface. It may be assumed that the peak is caused by signals corresponding to vapor masses. As shown in Fig.10, the vapor mass signals are distributed over a range of pulse widths, and the rise and decline on either side of the peak maximum is regarded as the range of the vapor mass hovering period (indicated as 'region of vapor mass' in Fig.10) and the pulse width corresponding to the peak maximum is defined as the hovering period. As shown in Fig.11, there are two peaks in the pulse spectrum when the heat flux approaches CHF for subcooling of $0 \mathrm{~K}$ and $10 \mathrm{~K}$. These two peaks may be attributed to successively detached vapor masses due to the effect of the wake of the preceding detached vapor mass. When the spectrum of pulse width has the two peaks, the slopes on the either sides of each of the two peaks (indicated as 'region 1' and 'region 2' in Fig.11) were regarded as the ranges of vapor mass hovering periods and both peaks were defined as the hovering period. The vapor mass hovering periods versus heat flux are shown in Fig.12. For each subcooling condition, the vapor mass hovering period tends to increase with increases in the heat flux until where the 2 nd peak appears in the pulse 
spectrum. Once the 2 nd peak appears for the $0 \mathrm{~K}$ and $10 \mathrm{~K}$ subcooling, the range of the vapor mass hovering period becomes extended to the shorter pulse width side. For the $20 \mathrm{~K}$ and $30 \mathrm{~K}$ subcooling which has no 2 nd peak, the vapor mass hovering periods are not strongly dependent on the degree of subcooling. So, as there is no marked decrease in the vapor mass hovering period, the duration of vapor mass hovering does not explain the increase in CHF with increased subcooling.

\subsection{Determination of the thickness of the macrolayer formed beneath vapor} masses

The changes in the probe signals, the void fractions, and the pulse frequencies measured at different heights over the heating surface indicate that the liquid-vapor structure above the heating surface consists of a region with a liquid layer remaining on the heating surface (region I) and a region further from the heating surface occupied by the vapor mass (region III). There is also an intermediate region (region II), where liquid or vapor dominates in turn probably due to the violent oscillations of the bottom of the vapor mass. It is considered that the peak of the pulse frequency profile shown in Fig. 7 is in region II, and the region where the void fraction profile (Fig.8) decreases corresponds to the neighborhood of the boundary between the regions II and III, however, it is difficult to determine the thickness of the macrolayer based on the profiles of time-averaged values such as the void fraction (Fig.8) or the pulse frequency (Fig.7). Therefore, the paper determines the macrolayer thickness based on the location where the vapor mass signals disappear. Vapor mass signals would be detected only when the probe tip is located in region III, and not when the probe tip is in the region II. The position where the vapor mass signals disappear, 
therefore gives the lowest boundary for region III. This paper defines the distance from the heating surface to this location as the macrolayer thickness.

To specify the position where the vapor mass signals disappear, the pulse obtained at each height was classified into groups for every millisecond of pulse width, and the frequency of the appearance of pulses belonging to each pulse group was plotted. An example is shown in Fig.13 with the frequencies of appearance for the $2-3 \mathrm{~ms}, 5-6 \mathrm{~ms}, 14-15 \mathrm{~ms}$ and $19-20 \mathrm{~ms}$ pulse groups plotted against the distance from the heating surface. For all pulse groups, the frequency of appearance decreases rapidly at distances smaller than $0.1 \mathrm{~mm}$ where they become zero or very nearly zero. The height at which the frequency of appearance reaches zero was determined for each pulse group and plotted in the top graph of Fig.14. Here, the height of disappearance of the pulse groups with very wide pulse widths (with very long hovering periods) are not included because the number of pulses for these groups are too few to show a smooth distribution of the frequency of appearance. The bottom graph of Fig.14 is the spectrum of pulse widths obtained with the fixed probe $4 \mathrm{~mm}$ over the heating surface under similar experimental conditions. Comparing the two graphs, it becomes possible to specify the location where the vapor mass signals disappear. The bottom graph shows vapor masses between pulse widths of about 8 and $30 \mathrm{~ms}$, and the top graph indicates that vapor masses with narrower pulse widths (with shorter hovering periods) are nearer to the heating surface. Thus, the macrolayer assumes different thicknesses depending on differences in the hovering period of the upper vapor masses. However, as the position of disappearance corresponding to the peak of the spectrum indicates the thickness of the macrolayer with the highest formation frequency, the average of several data points around the peak was considered to indicate the macrolayer thickness, 
and the furthest and the nearest locations of disappearance of the vapor masses (relative to the heating surface) were assumed to be the minimum and maximum thicknesses of the macrolayer. When the spectrum of the pulse width has two peaks, in the high heat flux region at subcooling of $0 \mathrm{~K}$ and $10 \mathrm{~K}$ as shown in Fig.15, two average values were calculated from several data points around the two peaks and these were defined as the thicknesses.

\subsection{Macrolayer thickness}

Figure 16 shows the macrolayer thickness for a range of heat fluxes, where the lowest heat flux in each subcooling condition, except for the saturated condition, is the heat flux at which the large vapor mass covering the whole area of the heating surface begins to form: the lowest heat flux of the vapor mass region. (For the saturated condition, such vapor masses are formed above a heat flux of about $1 \mathrm{MW} / \mathrm{m}^{2}$ ). The symbols are the central peak values and the vertical bars at each symbol indicate the minimum and maximum values. The two symbols plotted for the same heat flux with $0 \mathrm{~K}$ and $10 \mathrm{~K}$ subcooling are the values obtained from the two peaks of the pulse width spectrum. In the $20 \mathrm{~K}$ and $30 \mathrm{~K}$ subcooling the lowest heat flux of the vapor mass region exceeds the CHF of saturated boiling, and the thicknesses of the macrolayer at that heat flux is almost the same as those at high heat fluxes for saturated boiling, and then thins rapidly further with increases in the heat flux. There is no similar dependence of the thickness on the heat flux for the case of the $0 \mathrm{~K}$ and $10 \mathrm{~K}$ subcooling because of the two peaks in the pulse width spectrum, however the values corresponding to the peak of the narrower pulse width (shorter hovering period) show decreases with increases in the heat flux. As shown in Fig.16, the thicknesses of the macrolayer in both saturated and subcooled boiling are not expressed by a unique function of the heat 
flux like the various correlations previously proposed for saturated boiling, but they show different tendencies at different subcooling conditions.

Figure 17 compares the macrolayer thickness obtained in the present experiments under saturated conditions with the data of previous experiments. The results reported for the correlations proposed by Rajvanshi et al. [4], Kumada et al. [10], and the correlation that Bhat et al. [11] derived from the data of Iida et al. [1] are also shown in Fig.17. The thickness of macrolayer at lower heat fluxes where the pulse spectrum has the single peak established here, and the thickness determined from the peak of the wider pulse width (longer hovering period) at higher heat fluxes where the pulse spectrum has two peaks agree with the correlation of Bhat et al. However, the thicknesses corresponding to the peak of the narrower pulse width lie close to the Rajvanshi correlation. The correlation by Kumada et al. predicts a thinner macrolayer in the lower heat flux region. Here it must be borne in mind that none of the correlations in Fig. 17 have been used to predict the macrolayer in subcooled boiling.

The above results suggest the conclusion that when the CHF is caused by dryout of the macrolayer beneath the vapor mass, then the cause of the CHF increase with increasing subcooling may be that the lowest heat flux of the vapor mass region shifts towards the higher heat flux and that a thick macrolayer is able to form in subcooled boiling. As a next step, the mechanisms of macrolayer formation and the process of its dryout should be examined to clarify the CHF of saturated and subcooled boiling.

\section{Conclusions}

To examine the CHF mechanism in saturated and subcooled pool boiling, the liquid-vapor behavior near the heating surface was measured using conductance 
probes. The findings and conclusions obtained in this study may be summarized as follows:

(1) The void fraction distributions while the vapor mass hovers over the heating surface were obtained using the two conductance probes. There were no large differences in the liquid-vapor structure beneath the vapor mass once the vapor mass covers the heating surface in saturated and subcooled boiling.

(2) In the heat flux range where large vapor masses are formed at subcooling of $20 \mathrm{~K}$ and $30 \mathrm{~K}$, there is a liquid layer on the heating surface that does not dryout even at heat fluxes far higher than the CHF for saturated boiling.

(3) As the probe approaches the heating surface, the probe signals corresponding to the vapor masses become discontinuous, and then change form to an aggregation of narrow pulses. This suggests that the interface at the bottom of the vapor mass may oscillate intensively.

(4) Assuming that the region from the heating surface to the height below which the oscillation of the interface at the bottom of the vapor mass does not reach corresponds to the macrolayer, then the thickness of the macrolayer was specified from the location where the vapor mass signals disappear. It was found that the thickness of the macrolayer forming near the lowest heat flux of the vapor mass region in the $20 \mathrm{~K}$ and $30 \mathrm{~K}$ subcoolings are comparable to those formed at high heat fluxes in saturated boiling.

(5) If the CHF is caused by dryout of the macrolayer beneath the vapor mass, the reasons why the $\mathrm{CHF}$ increase with increases in subcooling may be that the lowest heat flux of the vapor mass region increases with increases in the subcooling and that a thicker macrolayer may be formed in subcooled boiling. 


\section{Captions of figures}

Figure 1 Experimental apparatus.

Figure 2 Measurement circuit.

Figure 3 Examples of the probe signals.

Figure 4 Boiling curves for different subcooling conditions.

Figure 5 Variation in CHF with subcooling.

Figure 6 Appearances of probe signals at different heights over the heating surface.

Top black set: moving probe. Bottom gray set: fixed probe.

Top of set: directly measured probe signal. Bottom of set: digitized signal.

Figure 7 Distributions of pulse frequencies and average pulse widths.

Figure 8 Distributions of time averaged void fractions based on time when the fixed probe detects vapor mass signals.

Figure 9 Thickness of liquid layer remaining on the heating surface without drying out for different subcooling conditions.

Figure 10 Spectrums of pulse widths (conditions with 1 peak).

Figure 11 Spectrums of pulse widths (conditions with 2 peaks).

Figure 12 Hovering periods of vapor masses.

Figure 13 Frequency distributions of 3, 6, 15 and $20 \mathrm{~ms}^{-}$wide pulses.

Figure 14 Positions where pulses disappear and incidence of pulses in 1 peak spectrums.

Figure 15 Positions where pulses disappear and incidence of pulses in 2 peak spectrums.

Figure 16 Macrolayer thickness versus heat flux.

Figure 17 Macrolayer thickness obtained in the present experiment at saturated condition with previously published data and correlations. 


\section{References}

[1] Y. Iida and K. Kobayasi, An experimental investigation on the mechanism of pool boiling phenomena by a probe method, Proceedings of the 4th International Heat Transfer Conference, Paris, 5(1970), 1-11.

[2] M. Shoji, A study of steady transition boiling of water: experimental verification of macrolayer evaporation model, Pool and External Flow Boiling, Dhir, V.K. et al. ed., ASME, (1992), 237-242.

[3] A.M. Bhat, J.S. Saini and R. Prakash, Role of macrolayer evaporation in pool boiling at high heat flux, International Journal of Heat and Mass Transfer 29(12) (1986) 1953-1961.

[4] A.K. Rajivanshi, J.S. Saini and R. Prakash, Investigation of macrolayer thickness in nucleate pool boiling, International Journal of Heat and Mass Transfer 35(2) (1992) 343-350.

[5] H. Auracher and W. Marquardt, Heat transfer characteristics and mechanisms along entire boiling curves under steady-state and transient conditions, International Journal of Heat and Fluid Flow 25(2) (2004) 223-242.

[6] S. Inada, Y. Miyasaka, R. Izumi and M. Kobayashi, Studies on boiling curves in subcooled pool boiling (4th, Heat transfer mechanism in transition boiling region), Transactions of JSME, 47(423) (1981) 2199-2208.

[7] S. Yokoya, M. Watanabe and M. Shoji, Critical heat flux in high subcooled pool boiling, Proceedings of 37th National Heat Transfer Symposium of Japan, (2000) $65-66$.

[8] J. Li, S. Yokoya, M. Watanabe, H. Yoshii and M. Shoji, Study of critical heat flux in subcooled pool bnoiling, Proceedings of 36th National Heat Transfer Symposium of Japan, (1999) 391-392.

[9] K. Stephan and M. Abdelsalam, Heat-transfer correlations for natural 
convection boiling, International Journal of Heat and Mass Transfer 23(1) (1980) 73-87.

[10] T. Kumada and H. Sakashita, Pool boiling heat transfer-II. Thickness of liquid macrolayer formed beneath vapor masses, International Journal of Heat and Mass Transfer 38(6) (1995) 979-987.

[11] A.M. Bhat, R.Prakash and J.S. Saini, On the mechanism of macrolayer formation in nucleate pool boiling at high heat flux, International Journal of Heat and Mass Transfer 26(5) (1983) 735-739. 


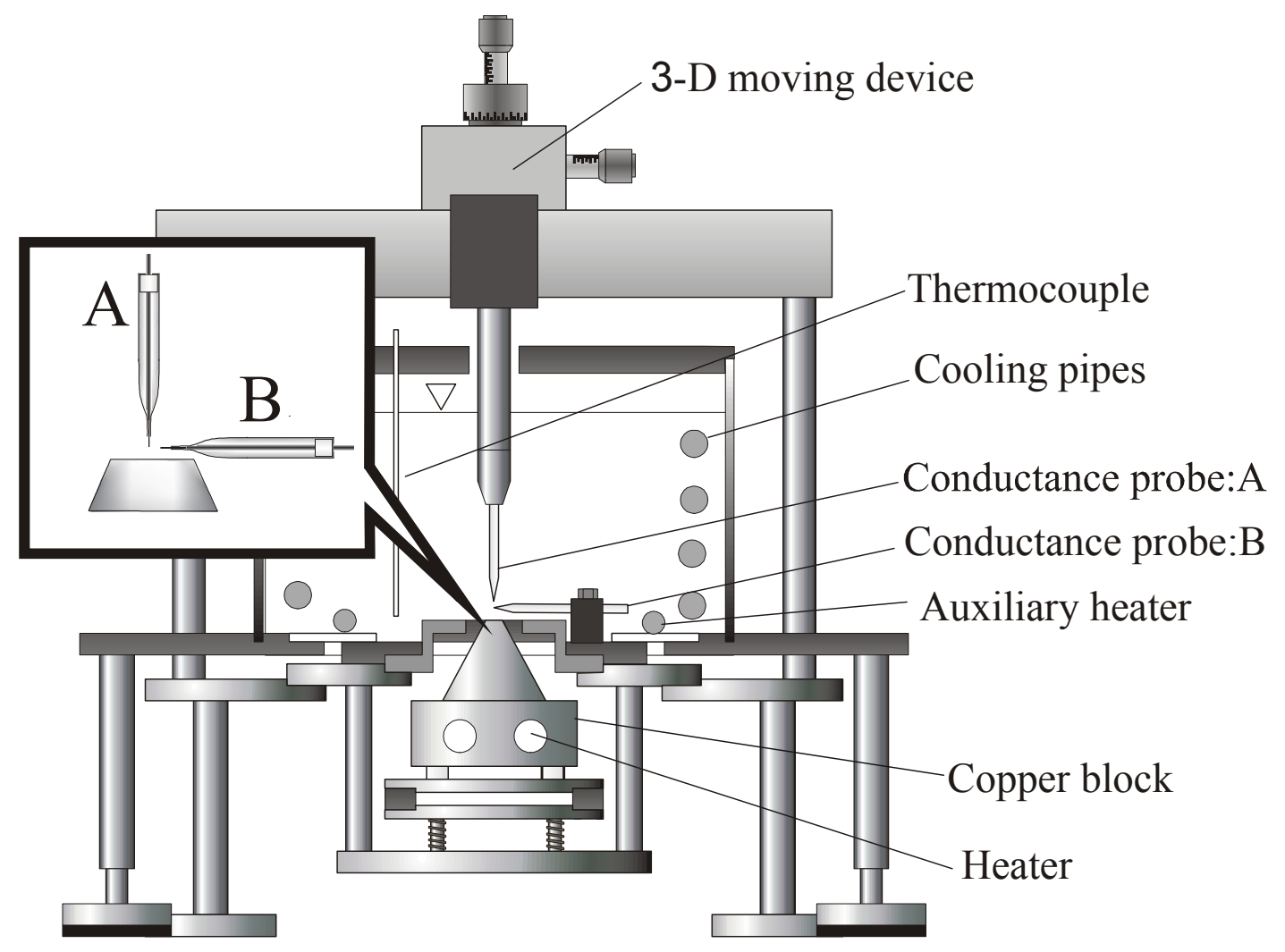

Figure 1 Experimental apparatus. 


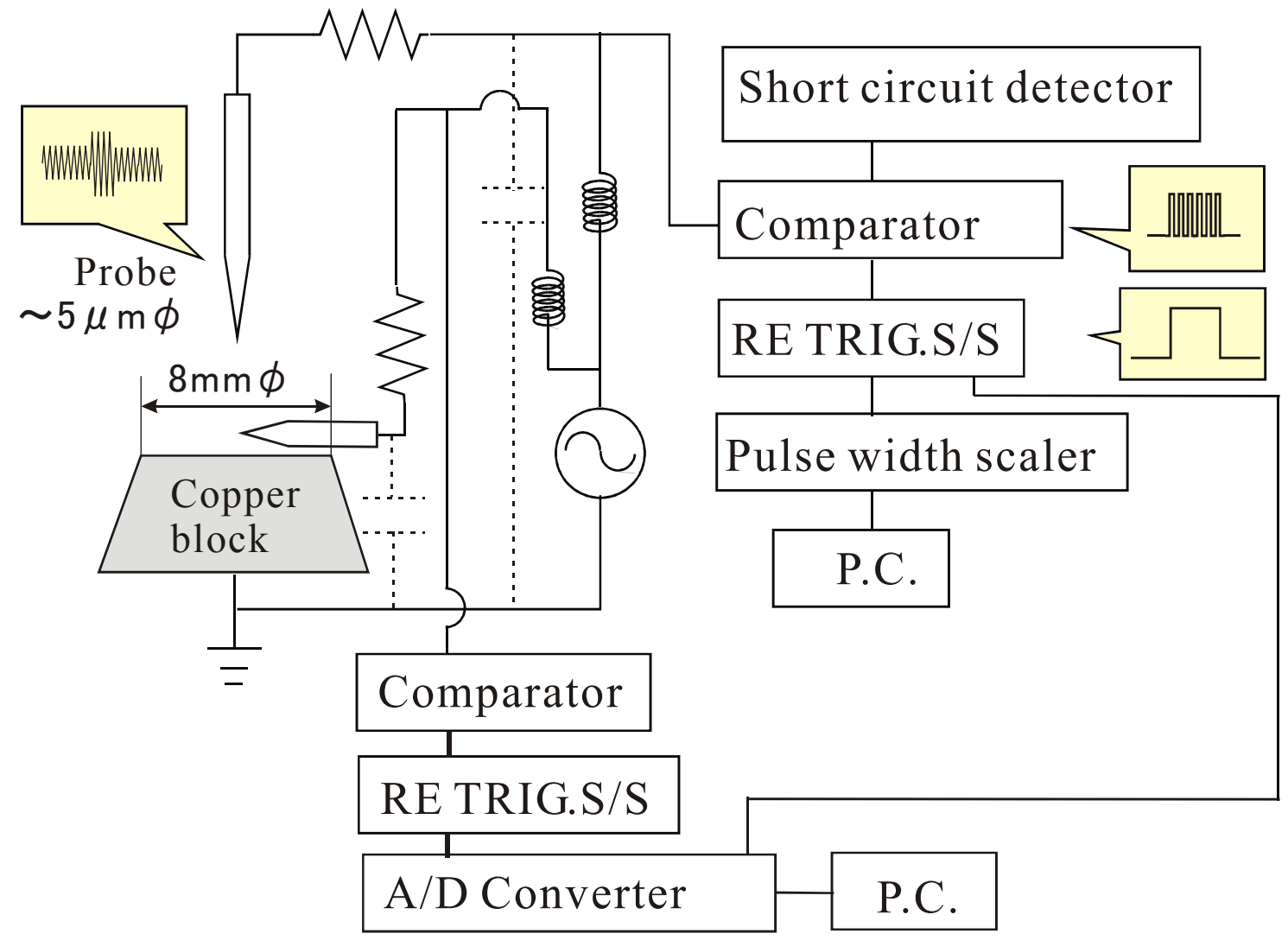

Figure 2 Measurement circuit. 


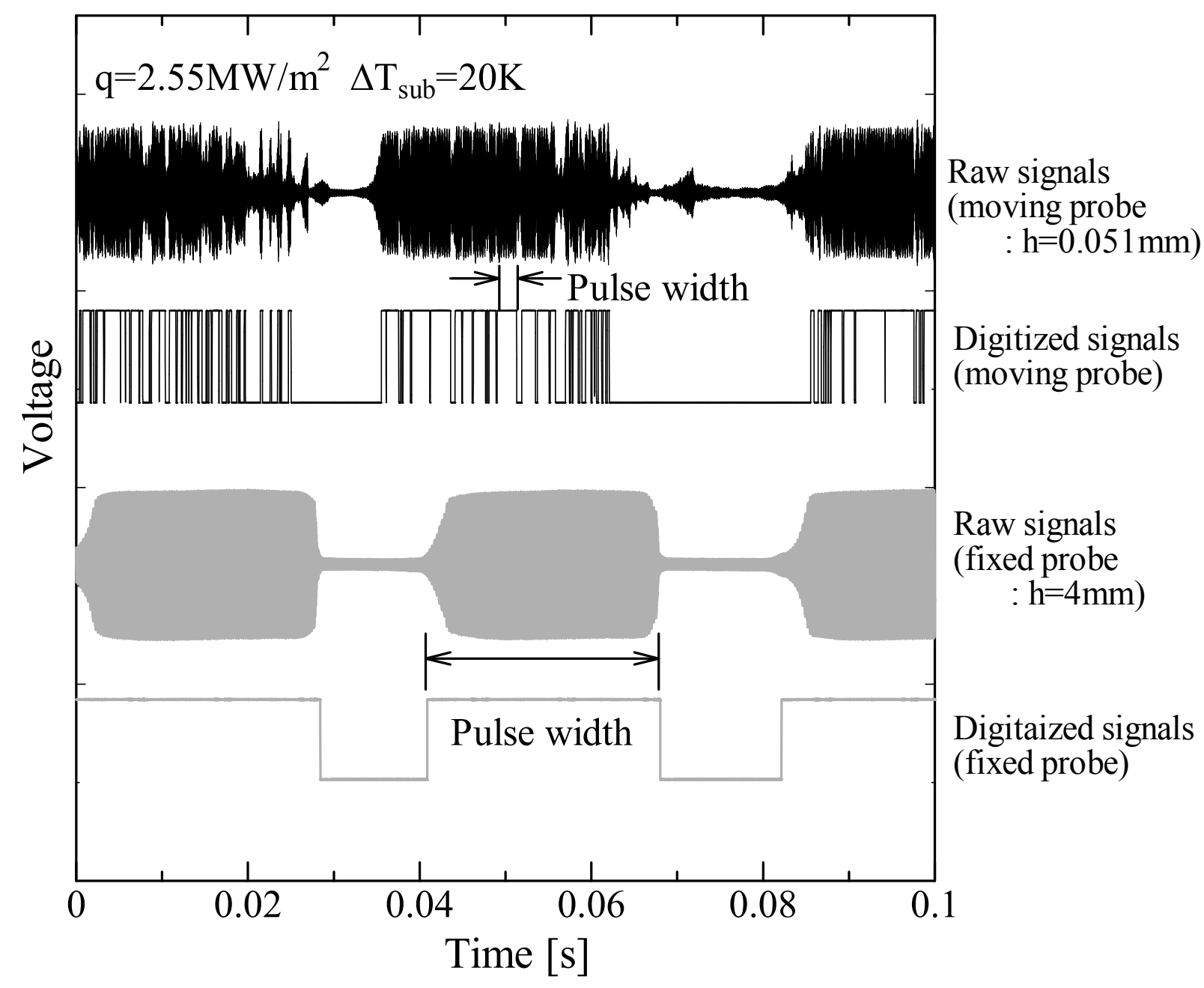

Figure 3 Examples of the probe signals. 


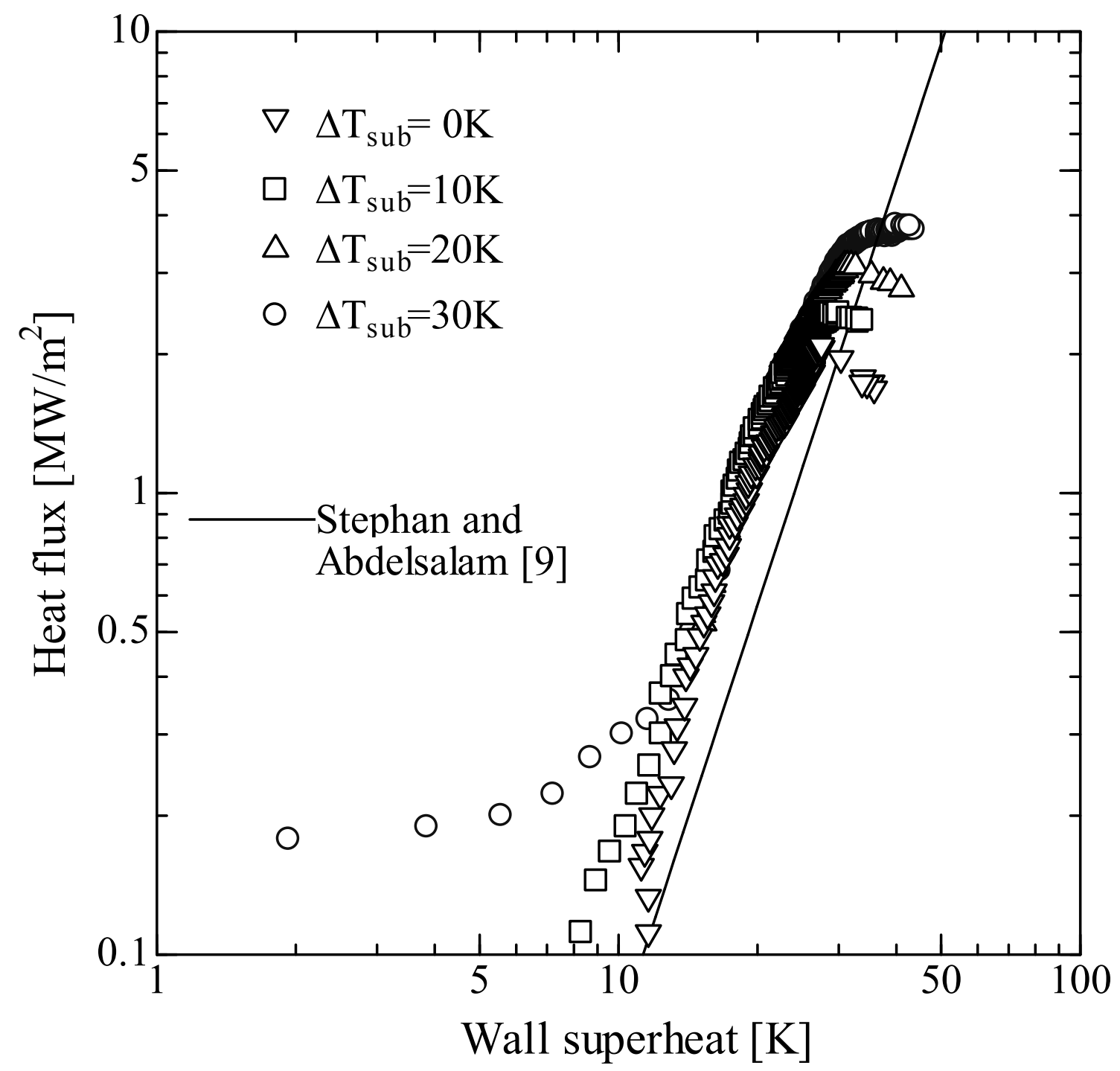

Figure 4 Boiling curves for different subcooling conditions. 


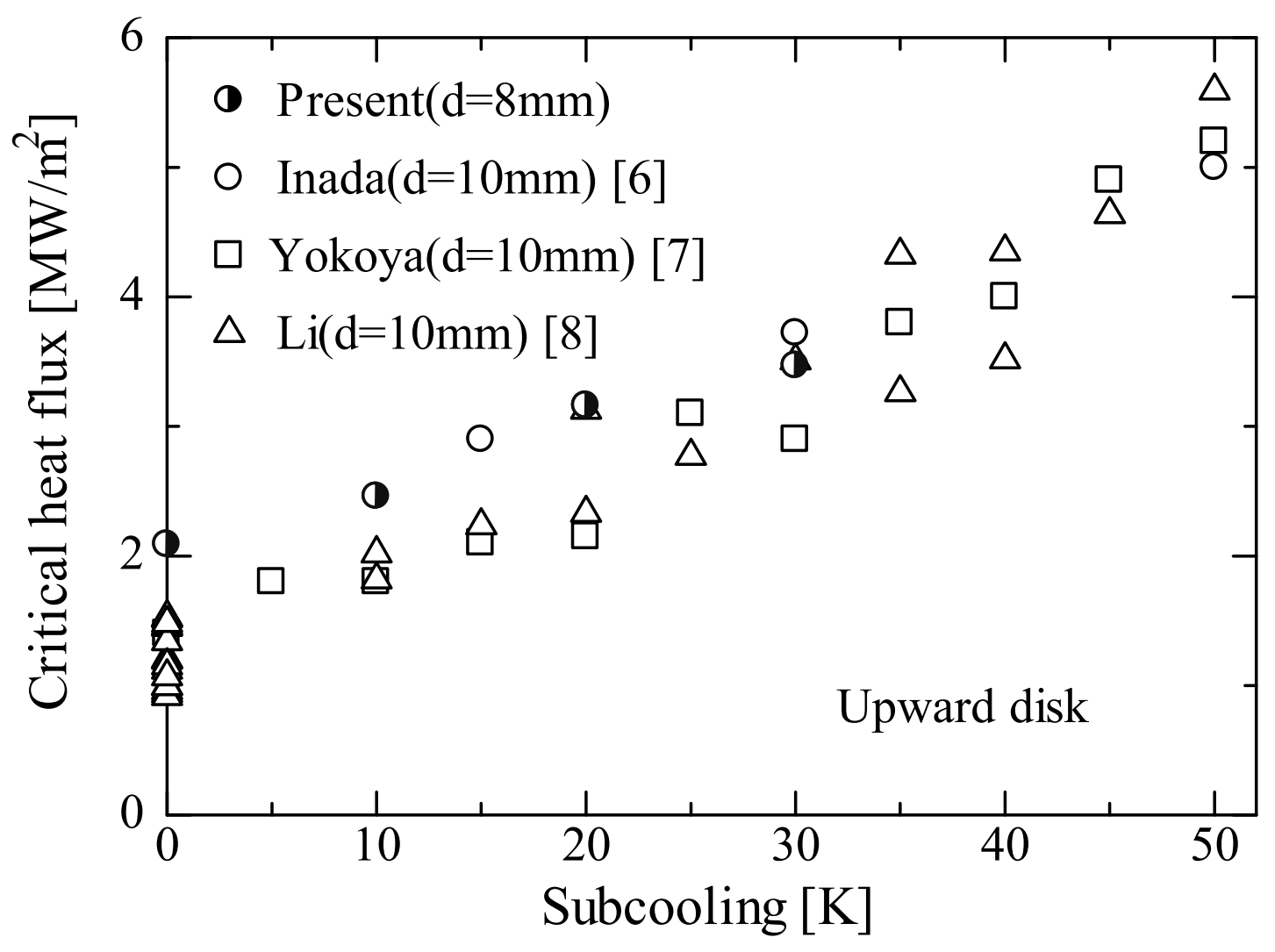

Figure 5 Variation of CHF with subcooling. 

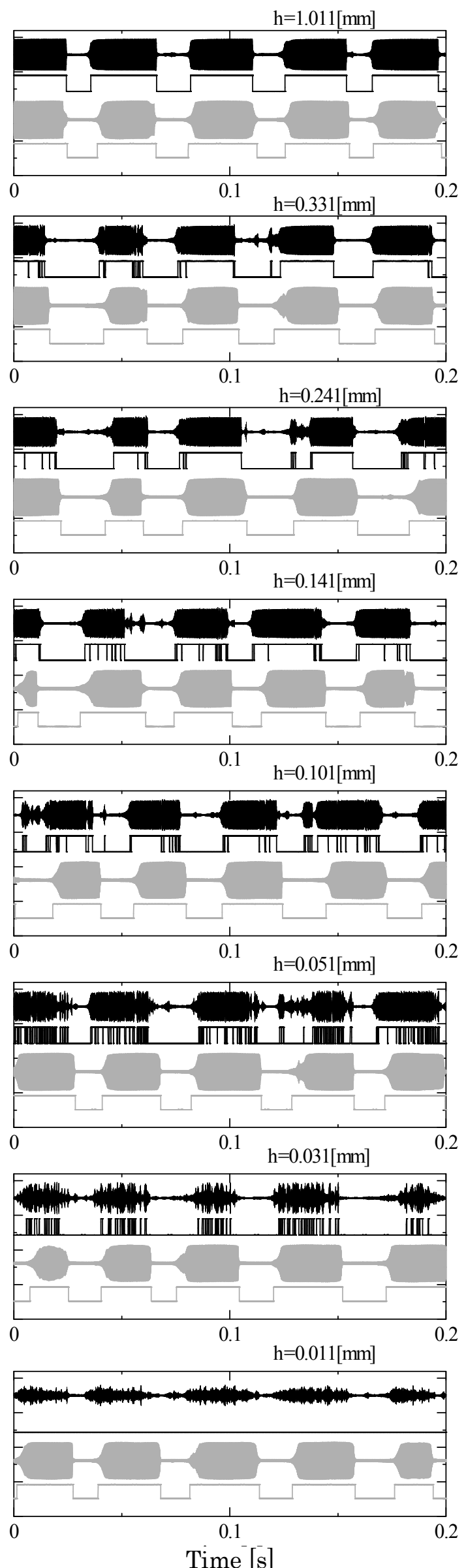

Figure 6 Appearances of probe signals at different heights (h) over the heating surface. Top black set: moving probe. Bottom gray set: fixed probe.

Top of set: directly measured probe signal. Bottom of set: digitized signal. 


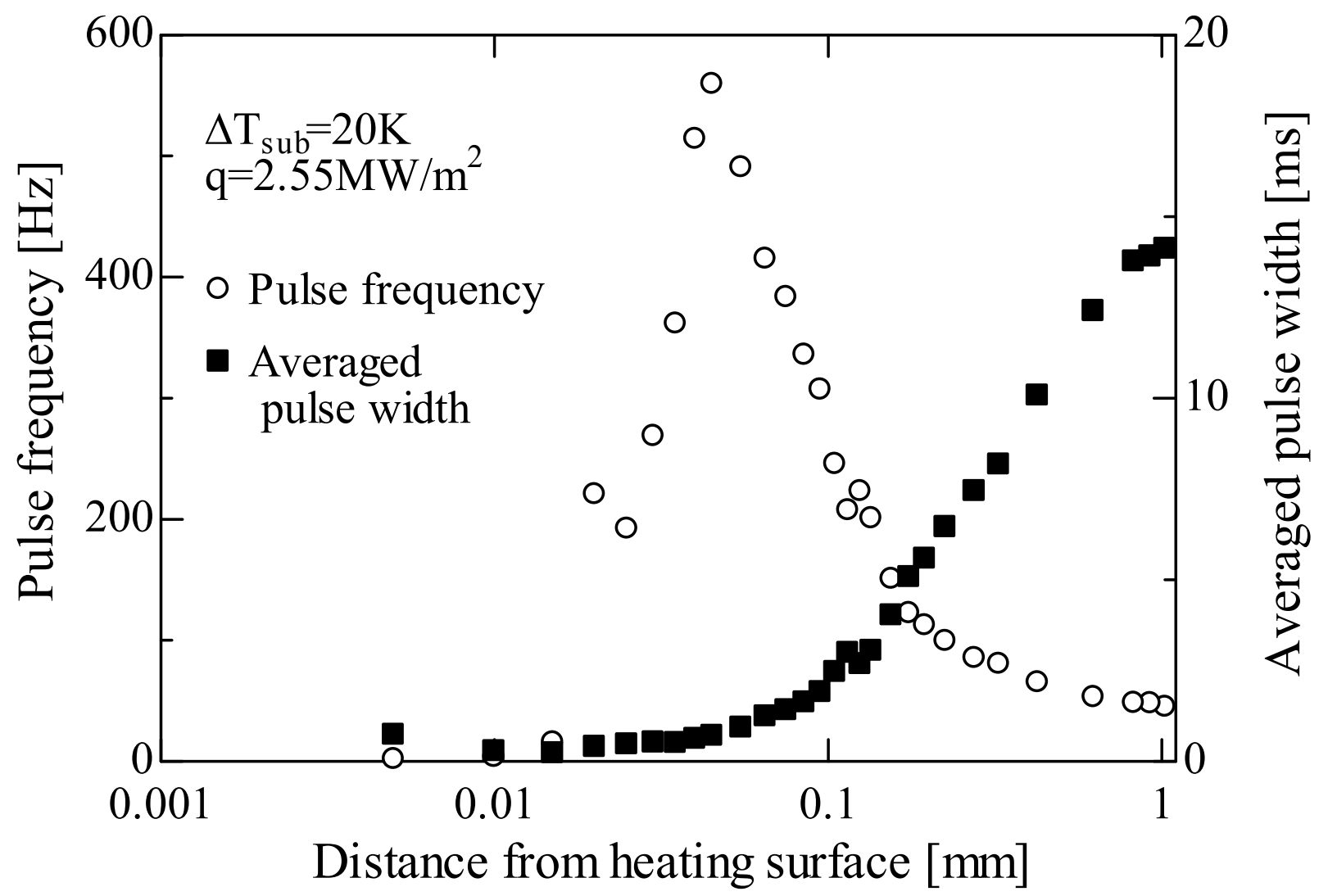

Figure 7 Distributions of pulse frequencies and average pulse widths. 


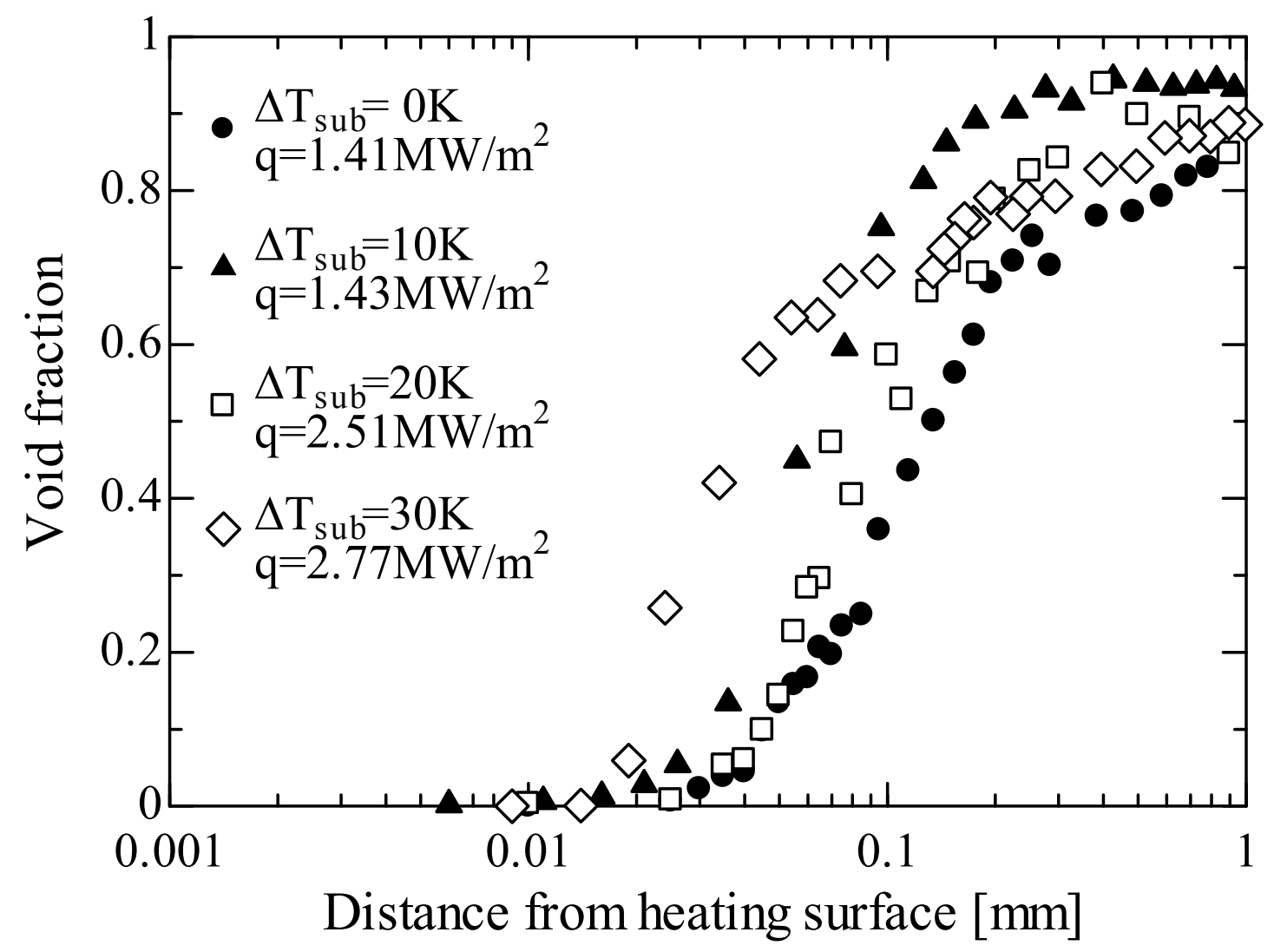

Figure 8 Distributions of time averaged void fractions based on time when the fixed probe detects vapor mass signals. 


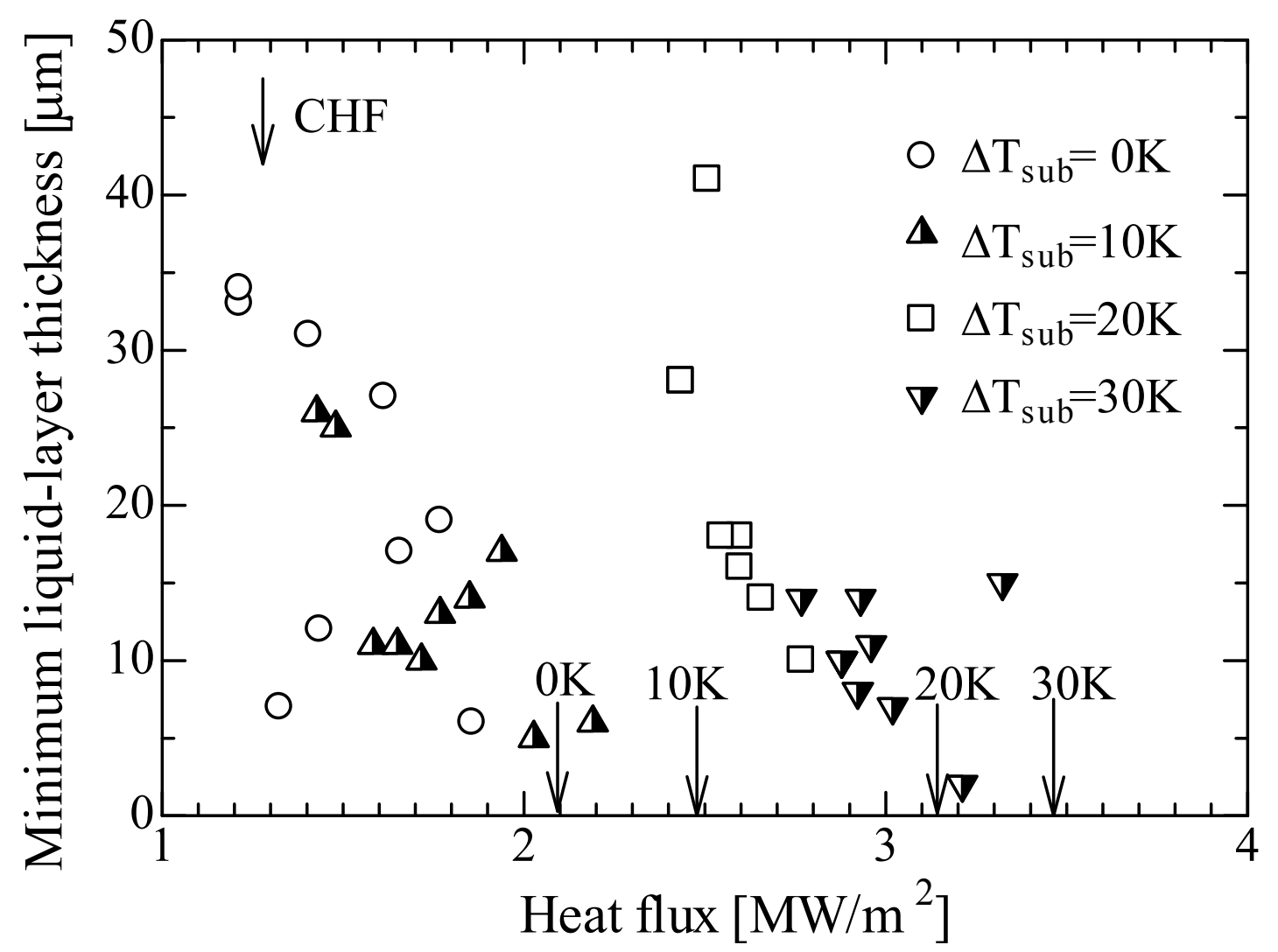

Figure 9 Thickness of liquid layer remaining on the heating surface without drying out for different subcooling conditions. 

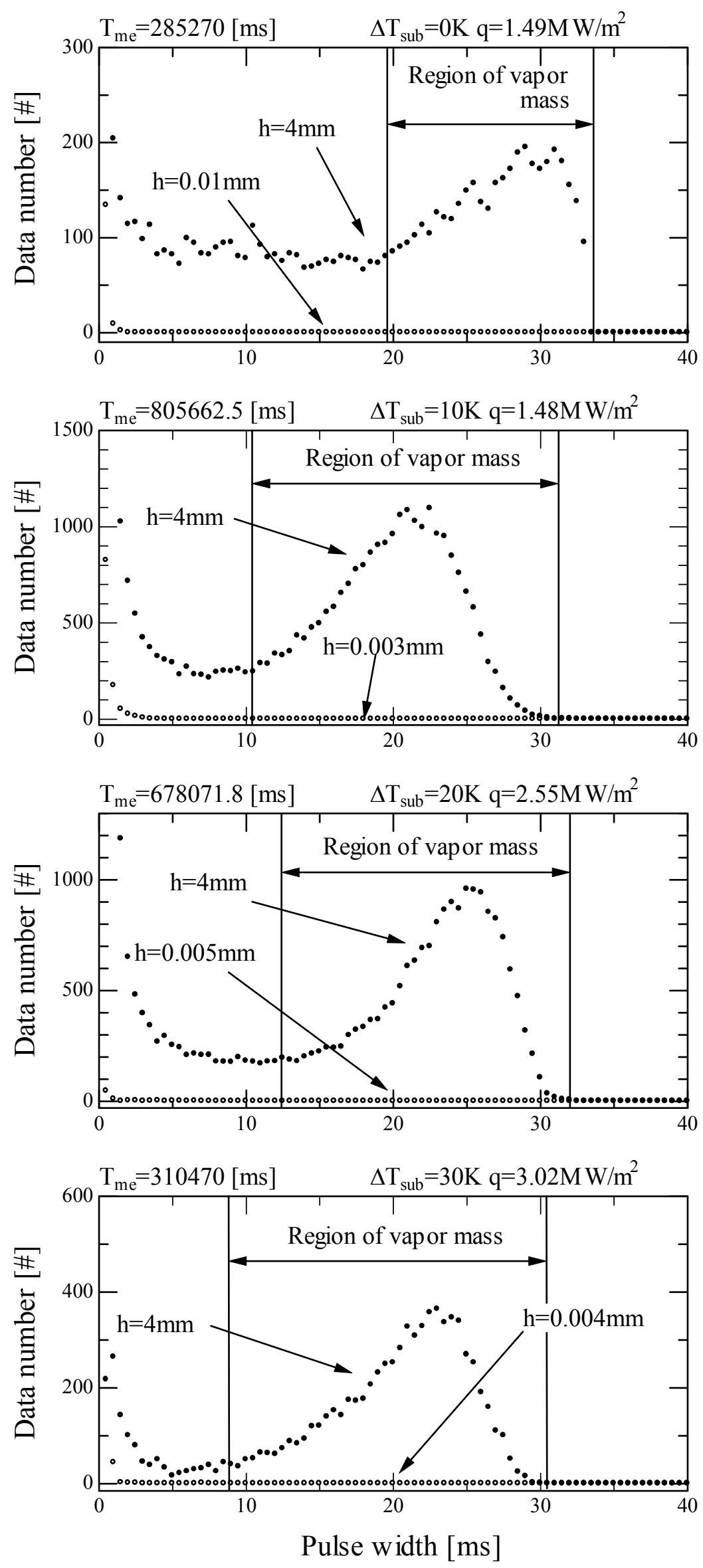

Figure 10 Spectrums of pulse widths (conditions with 1 peak). 

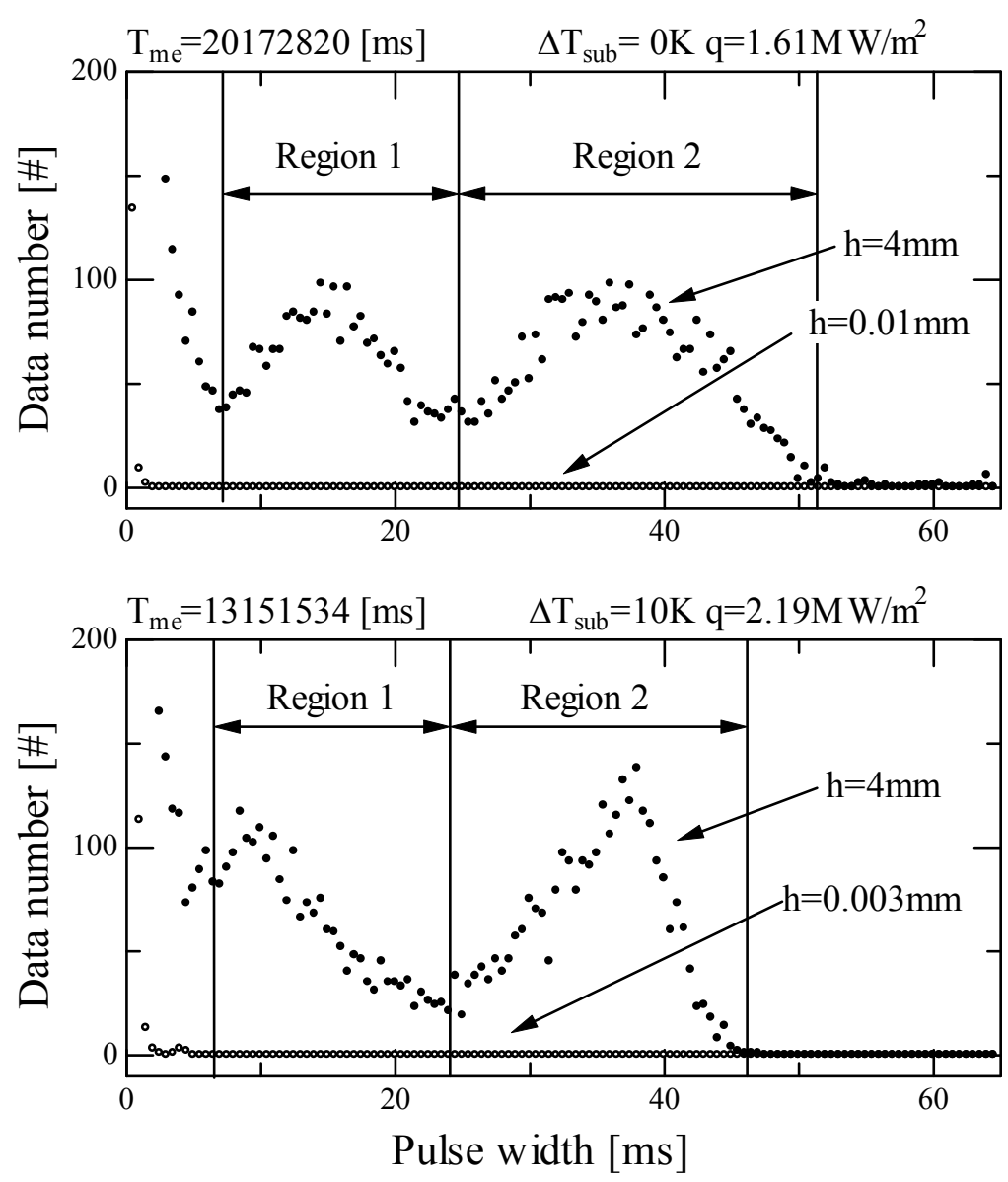

Figure 11 Spectrums of pulse widths (conditions with 2 peaks). 


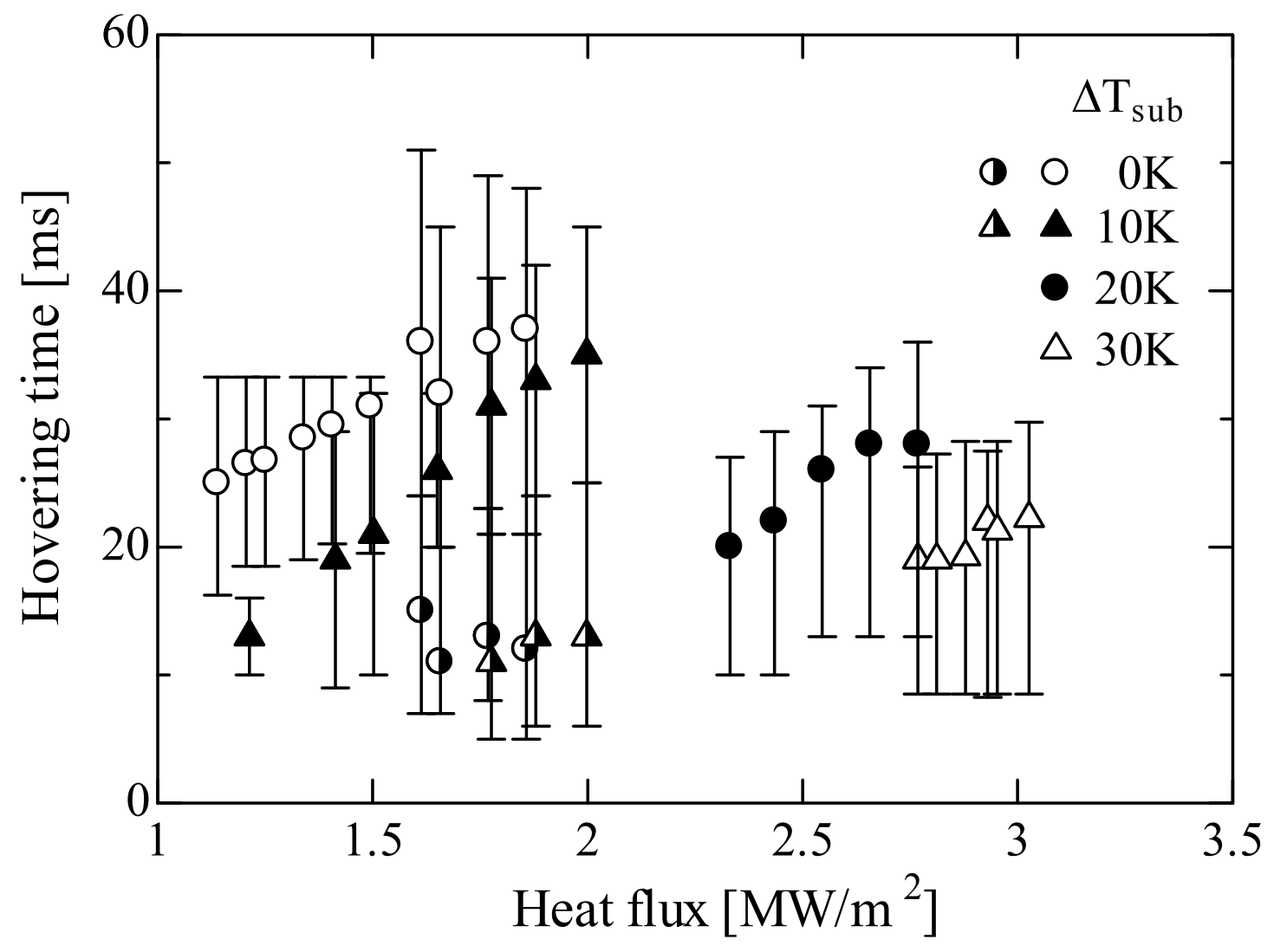

Figure 12 Hovering periods of vapor masses. 


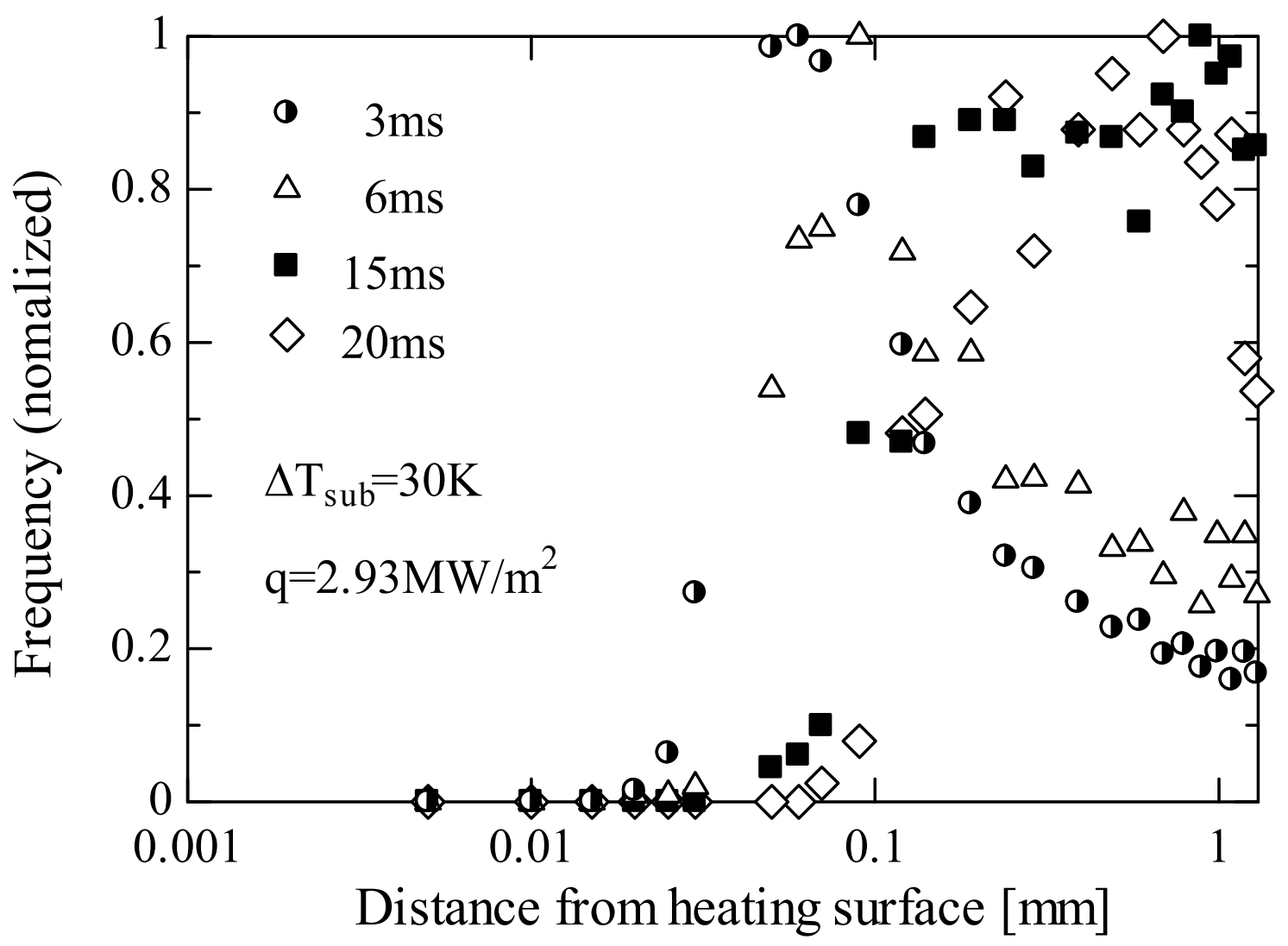

Figure 13 Frequency distributions of 3, 6, 15 and $20 \mathrm{~ms}^{-}$wide pulses. 


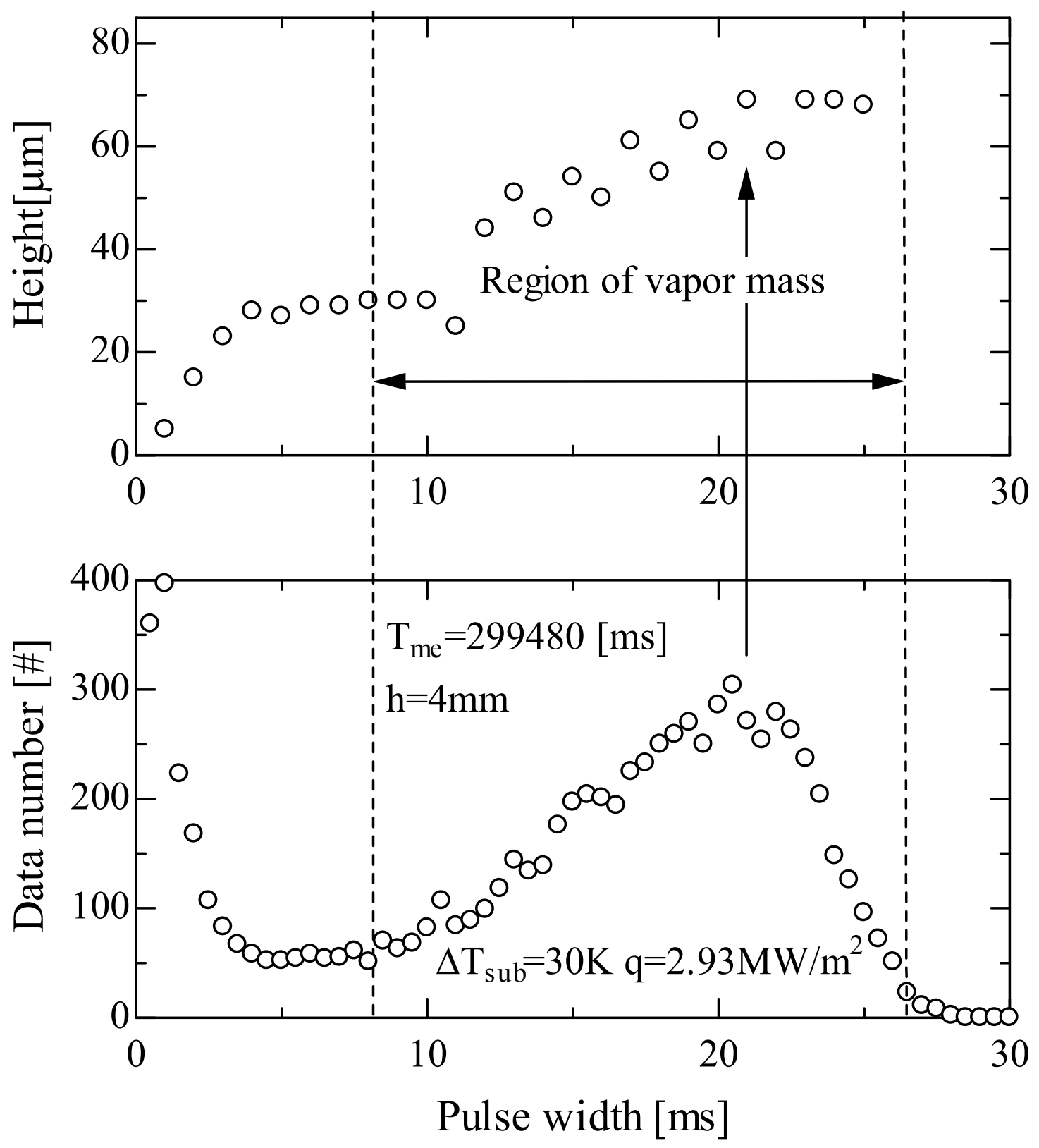

Figure 14 Positions where pulses disappear and incidence of pulses in 1 peak spectrums. 


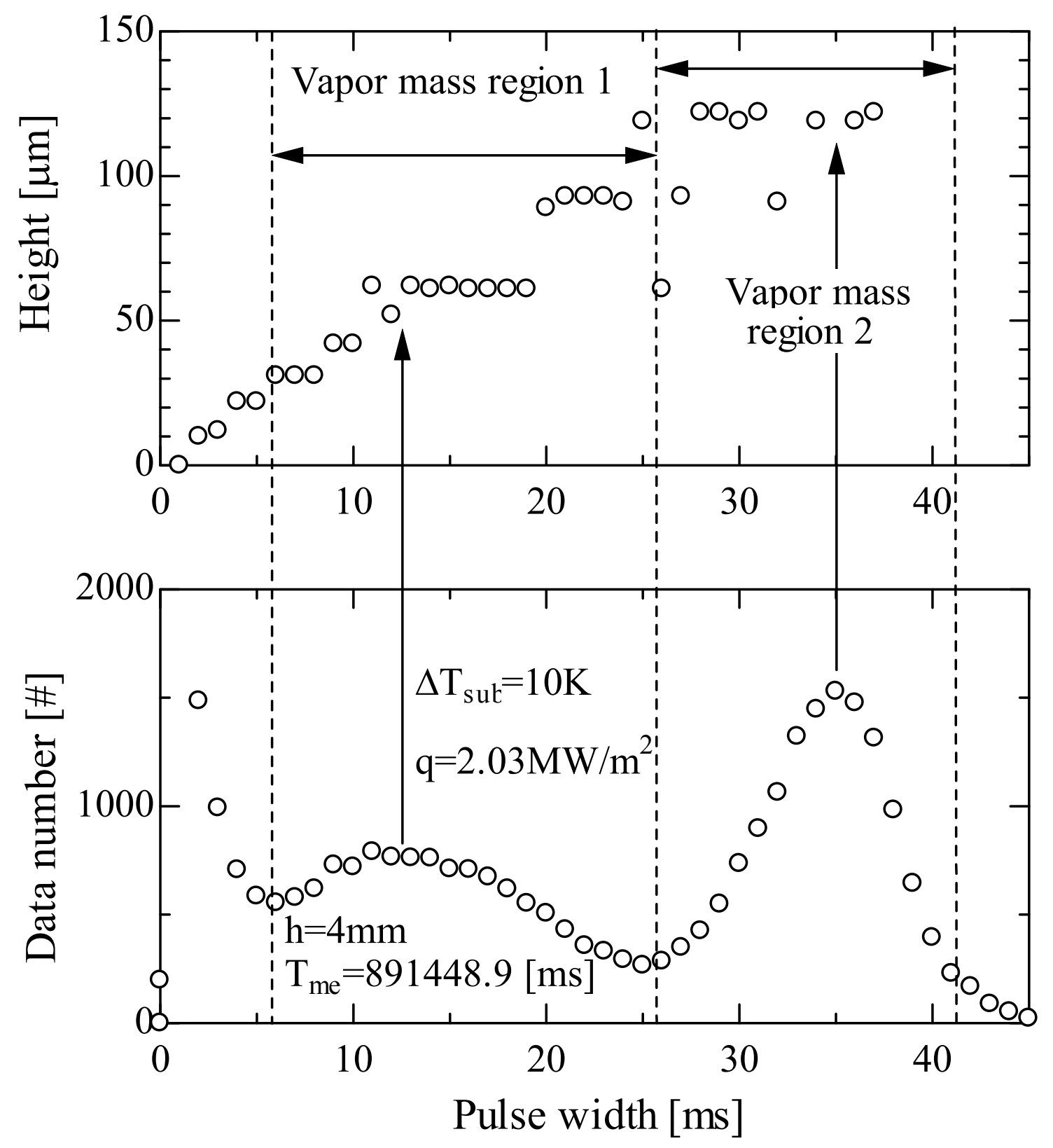

Figure 15 Positions where pulses disappear and incidence of pulses in 2 peak spectrums. 


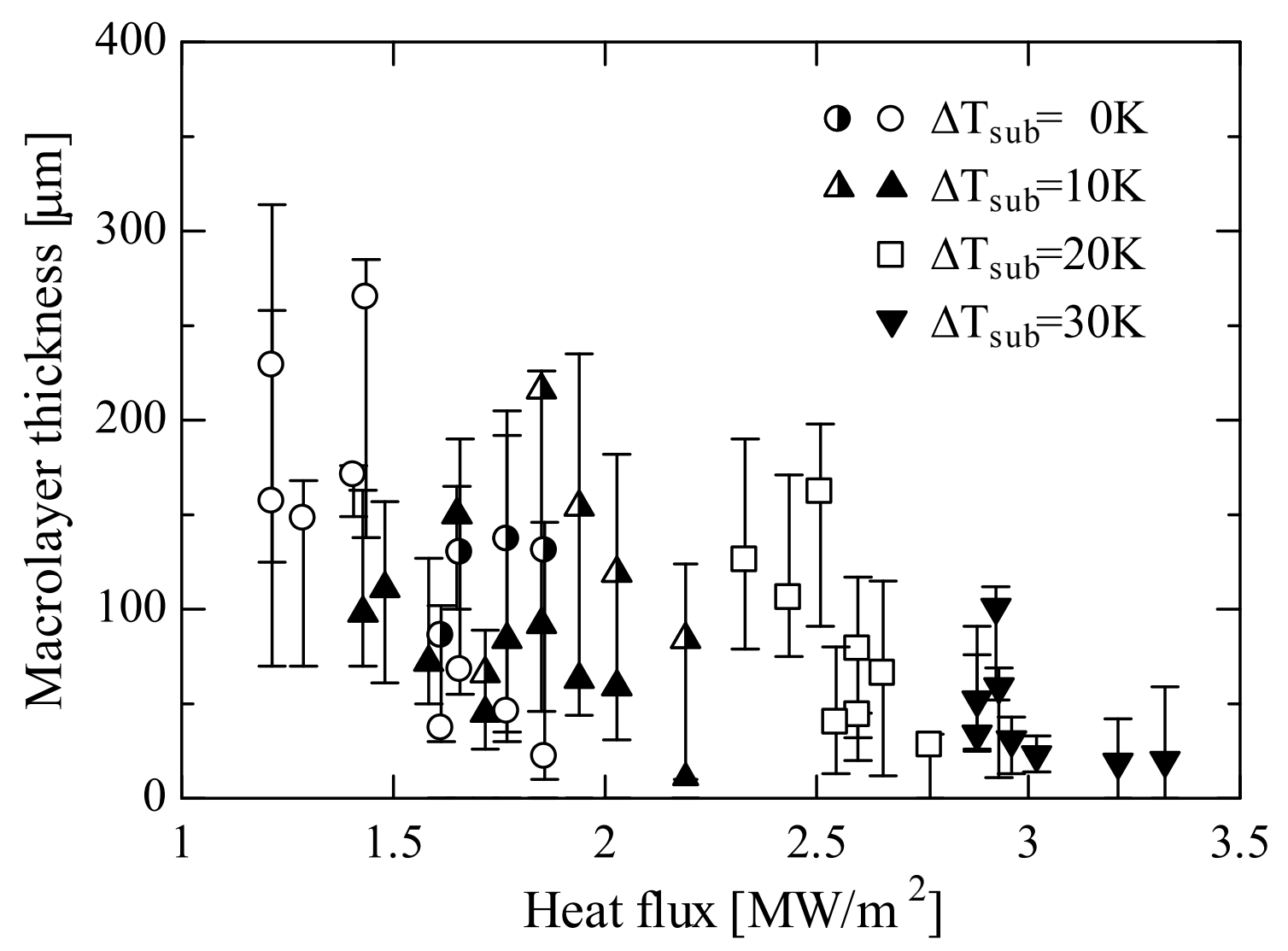

Figure 16 Macrolayer thickness versus heat flux. 


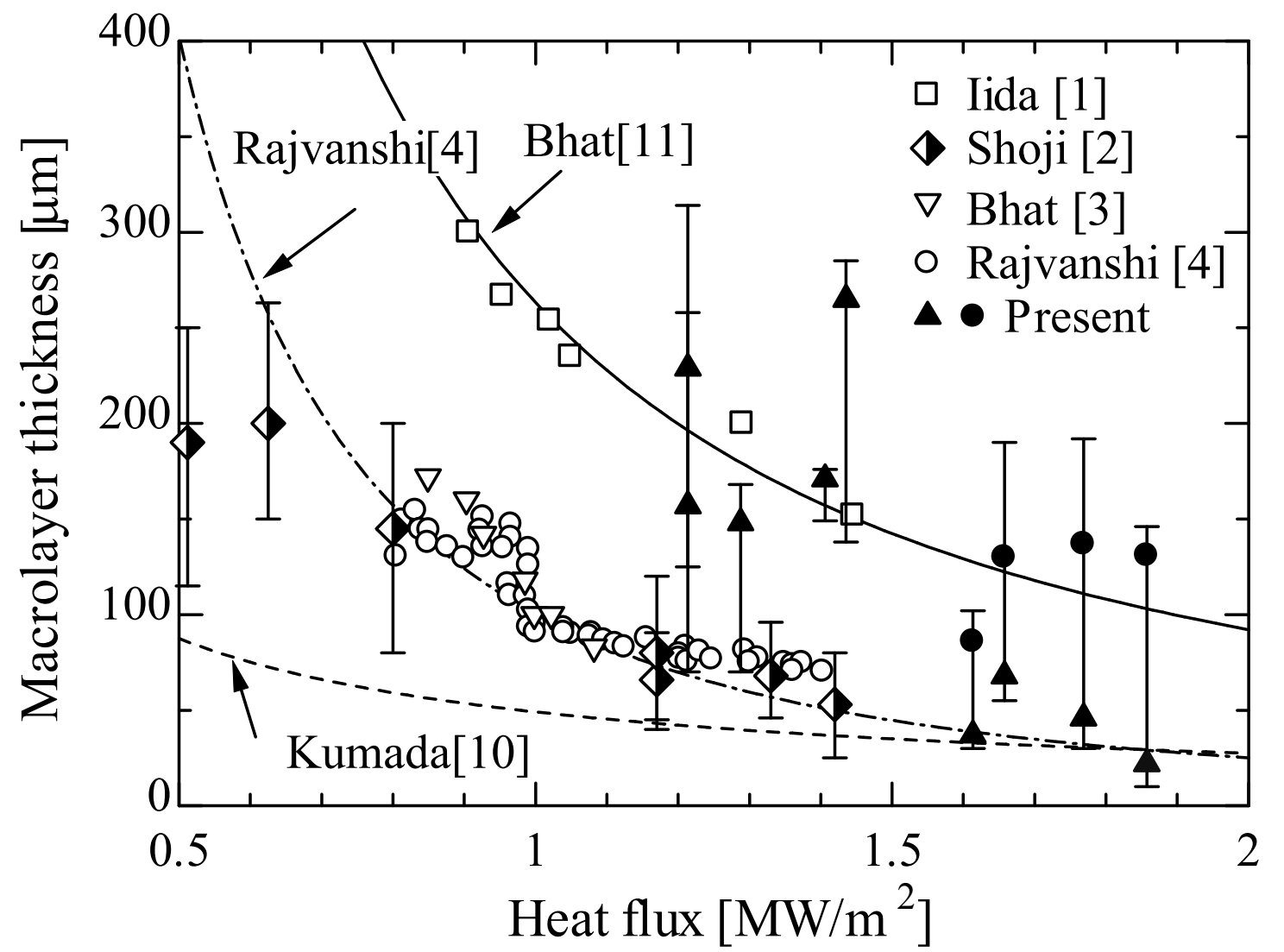

Figure 17 Macrolayer thickness obtained in the present experiment at saturated condition with previously published data and correlations. 